\title{
Corynebacterium argentoratense sp. nov., from the Human Throat
}

\author{
P. RIEGEL, ${ }^{1 *}$ R. RUIMY, ${ }^{2}$ D. DE BRIEL, ${ }^{1}$ G. PREVOST, ${ }^{1}$ F. JEHL, ${ }^{1}$ F. BIMET, ${ }^{3}$ \\ R. CHRISTEN, ${ }^{2}$ AND H. MONTEIL ${ }^{1}$ \\ Institut de Bactériologie de la Faculté de Médecine, Université Louis-Pasteur, Strasbourg, ${ }^{1}$ Centre National de \\ la Recherche Scientifique and Université Paris VI Station Zoologique, Villefranche sur Mer, ${ }^{2}$ \\ and Laboratoire des Identifications Bactériennes, Institut Pasteur, Paris, ${ }^{3}$ France
}

\begin{abstract}
A new Corynebacterium species, Corynebacterium argentoratense was isolated from the throats of four human patients. It is characterized by the presence of chemotype IV, a cell wall, corynomycolic acids, and a $G+C$ content ranging from 60 to $61 \mathrm{~mol} \%$. Strains belonging to this species exhibit high levels of DNA relatedness as determined by DNA-DNA hybridization experiments (S1 nuclease procedure) but no close DNA relatedness with related Corynebacterium species. Phylogenies based on comparative analyses of nearly complete smallsubunit rDNA sequences confirmed the inclusion of this new species within the genus Corynebacterium and grouped it in a cluster with $C$. diphtheriae, $C$. ulcerans, $C$. pseudotuberculosis, and $C$. kutscheri. PCR experiments revealed an absence of the gene coding for diphtheria toxin. This new species can be identified by its mycolic acid pattern, fermentation of sugars, and enzymatic activities. Strain IBS B10697 (CIP 104296) is the type strain of $C$. argentoratense.
\end{abstract}

The genus Corynebacterium contains irregular, gram-positive rods which have a type IV cell wall (arabinose, galactose, and meso-diaminopimelic acid) and short-chain mycolic acids (1). In a previous study that used high-performance liquid chromatography (HPLC) of mycolic acids as a tool for the identification of coryneform organisms, de Briel et al. observed that some strains exhibited a singular pattern which differed from that recognized for other Corynebacterium species (2). However, the estimated lengths of mycolic acids of these strains were in the range corresponding to Corynebacterium species. The bacteria had biochemical features, such as lack of nitrate reductase and urease activities and presence of acidification from glucose alone, which are characteristic of Corynebacterium flavescens and $C$. mycetoides, but pending further data they were referred to as Corynebacterium sp. In the present study, we determined the DNA base composition, the levels of DNA relatedness between four of these isolates and several Corynebacterium species, and their phylogenetic position by using comparisons of small-subunit rDNA sequences. On the basis of genomic data and phenotypic differences, we propose a new species for these strains, for which the name Corynebacterium argentoratense is proposed.

\section{MATERIALS AND METHODS}

Strains, media, and growth conditions. The four strains of Corynebacterium sp. (IBS B6369, IBS B10697, IBS B63473, and IBS B22070) were isolated at the Institute of Bacteriology of Strasbourg from patients hospitalized at the University Hospitals of Strasbourg, France. Each of these four strains exhibited a distinct ribotyping pattern with the PvuII restriction endonuclease. All these isolates were from throat specimens of patients suffering from tonsillitis. The type strains of established Corynebacterium species (C. amycolatum, C. cystitidis, $C$. diphtheriae, $C$. jeikeium, C. propinquum, C. renale, and $C$. striatum) were obtained from the Collection of the Pasteur Institute and the National Collection of Type Cultures for C. minutissimum NCTC $10288^{\mathrm{T}}$. Bacteria were grown aerobically at $37^{\circ} \mathrm{C}$ on Trypticase soy agar (bioMérieux, Marcy-l'Etoile, France) supplemented with $5 \%$ (vol/vol) sheep blood agar.

Biochemical tests. The API-Coryne system was used according to the manufacturer's instructions (bioMérieux) except for the time of incubation, which was fixed at $48 \mathrm{~h}$. Acid production from sugars was also tested by using a basal heart infusion (bioMérieux) at $25 \mathrm{~g}$ per liter, adjusted to $\mathrm{pH} 7.8$ and containing $1 \%$ (wt/vol) sugar, $0.1 \%$ Tween 80 (Merck, Darmstadt, Germany), and red phenol as

* Corresponding author. Mailing address: Institut de Bactériologie de la Faculté de Médecine, 3 rue Koeberlé, F-67000 Strasbourg, France. Phone: 3388211970 . Fax: 3388251113.

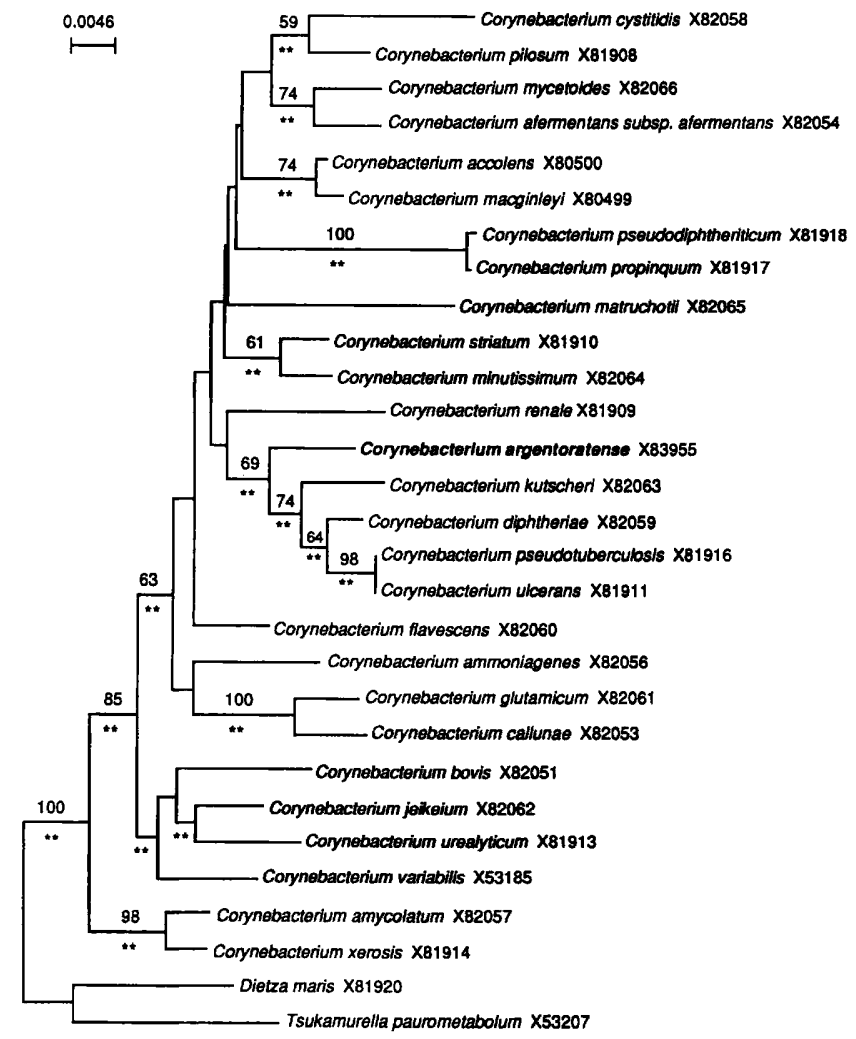

FIG. 1. Phylogenetic position of $C$. argentoratense within the genus Corynebacterium. The unrooted tree summarizes the results of phylogenetic analyses using three different methods based on the comparisons of small-subunit rDNA sequences of Corynebacterium species (12) and of their closest outgroup, represented by $D$. manis and $T$. paurometabolum. The topology shown was obtained by a neighbor-joining method. Asterisks, branches that were also found by maximum likelihood $(P<0.01)$. The percentages of bootstrap replications are indicated (heuristic search; only values greater than $50 \%$ are shown); these are branches found in the most parsimonious tree. Scale bar, accumulated changes per nucleotide. Domains used for these analyses correspond to positions 126 to 138,141 to 180,232 to 417,422 to 440,492 to 600,618 to 836,881 to 928,932 to 998,1040 to 1131,1137 to 1250,1265 to 1283 , and 1286 to 1355 (E. coli numbering). Organism names are followed by EMBL accession numbers. 
TABLE 1. Similarity matrix based on small-subunit rDNA sequences

\begin{tabular}{|c|c|c|c|c|c|c|c|c|c|c|c|c|c|c|c|c|c|c|c|c|c|c|c|c|c|c|c|}
\hline \multirow{2}{*}{ Strain } & \multicolumn{27}{|c|}{$\%$ Similarity } \\
\hline & 1 & 2 & 3 & 4 & 5 & 6 & 7 & 8 & 9 & 10 & 11 & 12 & 13 & 14 & 15 & 16 & 17 & 18 & 19 & 20 & 21 & 22 & 23 & 24 & 25 & 26 & 27 \\
\hline 1. C. argentoratense & 100 & & & & & & & & & & & & & & & & & & & & & & & & & & \\
\hline 2. C. accolens & 94.4 & & & & & & & & & & & & & & & & & & & & & & & & & & \\
\hline 3. C. afermentans subsp. afermentans & 93.7 & 94.5 & & & & & & & & & & & & & & & & & & & & & & & & & \\
\hline 4. C. amoniagenes & 93.4 & 93.1 & 92.7 & & & & & & & & & & & & & & & & & & & & & & & & \\
\hline 5. C. amycolatum & 93.8 & 92.4 & 93.0 & 93.1 & & & & & & & & & & & & & & & & & & & & & & & \\
\hline 6. C. bovis & 93.8 & 93.1 & 92.8 & 93.0 & 93.8 & & & & & & & & & & & & & & & & & & & & & & \\
\hline 7. C. callunae & 92.7 & 92.5 & 91.7 & 93.5 & 92.0 & 92.5 & & & & & & & & & & & & & & & & & & & & & \\
\hline 8. C. cystitidis & 91.5 & 94.1 & 93.4 & 91.5 & 91.6 & 91.7 & 91.0 & & & & & & & & & & & & & & & & & & & & \\
\hline 9. C. diphtheriae & 96.1 & 94.7 & 94.3 & 94.3 & 93.5 & 95.1 & 93.1 & 92.2 & & & & & & & & & & & & & & & & & & & \\
\hline 10. C. flavescens & 94.8 & 94.8 & 92.9 & 94.9 & 93.5 & 93.8 & 93.3 & 92.9 & 94.9 & & & & & & & & & & & & & & & & & & \\
\hline 11. C. glutamicum & 92.8 & 92.9 & 92.9 & 93.6 & 92.3 & 93.5 & 96.3 & 92.0 & 93.5 & 93.6 & & & & & & & & & & & & & & & & & \\
\hline 12. C. jeikeium & 93.2 & 94.5 & 92.9 & 93.1 & 93.6 & 95.1 & 91.9 & 91.6 & 93.9 & 93.9 & 92.8 & & & & & & & & & & & & & & & & \\
\hline 13. C. kutscheri & 94.8 & 93.9 & 94.2 & 93.4 & 92.9 & 93.2 & 91.5 & 91.6 & 96.3 & 93.9 & 92.5 & 92.6 & & & & & & & & & & & & & & & \\
\hline 14. C. macginleyi & 94.2 & 98.5 & 94.6 & 92.8 & 92.8 & 93.7 & 91.7 & 94.5 & 94.7 & 94.5 & 92.5 & 94.8 & 93.8 & & & & & & & & & & & & & & \\
\hline 15. C. matruchotii & 91.6 & 91.6 & 91.3 & 90.3 & 90.2 & 90.9 & 88.9 & 89.7 & 91.9 & 91.8 & 89.6 & 91.5 & 91.4 & 91.8 & & & & & & & & & & & & & \\
\hline 16. C. minutissimum & 95.9 & 97.3 & 94.3 & 94.0 & 92.9 & 94.0 & 93.3 & $93: 3$ & 94.8 & 95.4 & 93.4 & 94.8 & 93.3 & 96.5 & 92.3 & & & & & & & & & & & & \\
\hline 17. C. mycetoides & 93.4 & 93.8 & 95.7 & 92.0 & 92.0 & 92.0 & 91.6 & 93.0 & 93.2 & 92.7 & 92.3 & 91.8 & 92:1 & 93.4 & 90.1 & 94.6 & & & & & & & & & & & \\
\hline 18. C. pilosum & 93.6 & 93.7 & 93.2 & 94.1 & 92.4 & 92.5 & 92.2 & 94.0 & 94.0 & 94.2 & 93.1 & 92.4 & 93.0 & 93.5 & 90.9 & 94.4 & 93.5 & & & & & & & & & & \\
\hline 19. C. propinquum & 93.1 & 94.4 & 93.4 & 92.2 & 92.2 & 92.6 & 90.9 & 91.4 & 93.2 & 92.9 & 91.7 & 93.5 & 92.0 & 94.4 & 90.8 & 94.6 & 92.0 & 92.5 & & & & & & & & & \\
\hline 20. C. pseudodiphtheriticum & 93.4 & 94.2 & 93.1 & 92.4 & 92.7 & 93.0 & 90.9 & 91.6 & 93.6 & 93.0 & 91.4 & 93.6 & 92.1 & 94.1 & 90.8 & 94.4 & 92.1 & 92.4 & 99.0 & & & & & & & & \\
\hline 21. C. pseudotuberculosis & 95.5 & 94.4 & 93.9 & 93.2 & 93.0 & 94.8 & 92.5 & 91.4 & 97.7 & 94.2 & 93.1 & 93.4 & 95.5 & 94.6 & 91.7 & 95.0 & 92.6 & 92.9 & 93.6 & 93.6 & & & & & & & \\
\hline 22. C. renale & 94.1 & 94.6 & 94.2 & 93.1 & 93.4 & 93.2 & 92.1 & 92.7 & 95.0 & 93.7 & 92.3 & 92.9 & 94.7 & 94.6 & 91.3 & 94.6 & 93.8 & 94.1 & 92.8 & 92.8 & 94.6 & & & & & & \\
\hline 23. C. striatum & 94.9 & 94.9 & 93.5 & 94.2 & 92.3 & 93.8 & 93.2 & 92.5 & 95.0 & 95.4 & 93.2 & 92.8 & 93.6 & 94.9 & 92.3 & 97.3 & 92.9 & 93.4 & 92.9 & 92.7 & 94.9 & 93.4 & & & & & \\
\hline 24. C. ulcerans & 96.0 & 94.5 & 94.2 & 93.5 & 93.2 & 95.0 & 92.5 & 91.7 & 98.1 & 94.4 & 93.2 & 93.4 & 95.7 & 94.9 & 91.7 & 95.5 & 93.1 & 93.4 & 93.8 & 93.7 & 99.3 & 94.9 & 95.3 & & & & \\
\hline 25. C. urealyticum & 94.3 & 94.7 & 92.7 & 92.8 & 93.5 & 94.9 & 92.0 & 91.5 & 94.0 & 93.6 & 92.5 & 96.3 & 93.3 & 94.4 & 90.7 & 94.7 & 92.1 & 92.6 & 93.1 & 93.1 & 93.7 & 94.3 & 92.7 & 94.0 & & & \\
\hline 26. C. variabilis & 94.2 & 94.1 & 93.1 & 93.4 & 94.1 & 95.1 & 93.8 & 91.3 & 94.7 & 94.3 & 93.8 & 94.9 & 92.8 & 93.8 & 90.7 & 94.7 & 92.1 & 92.7 & 92.8 & 92.9 & 94.3 & 94.1 & 94.4 & 94.4 & 94.7 & & \\
\hline 27. C. xerosis & 93.5 & 92.8 & 92.2 & 93.9 & 97.0 & 94.7 & 92.8 & 91.2 & 93.8 & 94.0 & 93.3 & 93.5 & 92.5 & 93.4 & 89.7 & 93.5 & 91.5 & 92.9 & 92.4 & 92.4 & 93.6 & 93.2 & 93.2 & 93.7 & 93.5 & 94.8 & 100 \\
\hline
\end{tabular}

${ }^{a}$ For 1,314 nucleotides. 
TABLE 2. Characteristics used for differentiation of $C$. argentoratense from Corynebacterium species and related organisms ${ }^{a}$

\begin{tabular}{|c|c|c|c|c|c|c|c|c|}
\hline \multirow{2}{*}{ Organism } & \multirow{2}{*}{$\begin{array}{l}\text { Lipid } \\
\text { requirement }\end{array}$} & \multirow{2}{*}{ Urease } & \multirow{2}{*}{$\begin{array}{c}\text { Nitrate } \\
\text { reductase }\end{array}$} & \multirow{2}{*}{ Pyrazinamidase } & \multirow{2}{*}{$\begin{array}{c}\text { Alkaline } \\
\text { phosphatase }\end{array}$} & \multicolumn{3}{|c|}{ Acid from: } \\
\hline & & & & & & Glucose & Sucrose & Maltose \\
\hline C. argentoratense & - & - & - & + & $v^{b}$ & + & - & - \\
\hline C. accolens & + & - & + & $\mathbf{v}$ & - & + & $\mathrm{v}$ & - \\
\hline $\begin{array}{l}\text { C. afermentans subsp. } \\
\text { afermentans }\end{array}$ & - & - & - & + & + & - & - & - \\
\hline C. afermentans subsp. lipophilum & + & - & - & + & + & - & - & - \\
\hline C. amycolatum ${ }^{c}$ & - & $\mathrm{v}$ & $\mathrm{v}$ & + & + & + & $\mathrm{v}$ & $\mathrm{v}$ \\
\hline C. bovis & + & - & - & $\mathbf{v}$ & + & + & - & - \\
\hline C. diphtheriae & - & - & $\mathrm{v}$ & - & - & + & - & + \\
\hline C. flavescens & - & - & - & - & - & + & - & - \\
\hline C. jeikeium ${ }^{e}$ & + & - & - & + & + & + & - & $\mathbf{v}$ \\
\hline C. macginleyi & + & - & + & - & + & + & + & - \\
\hline C. minutissimum & - & - & - & + & + & + & $\mathrm{v}$ & + \\
\hline C. mycetoides & - & - & - & - & + & + & - & - \\
\hline C. propinquum & - & - & + & $\mathrm{v}$ & $\mathrm{v}$ & - & - & - \\
\hline C. pseudodiphtheriticum & - & + & + & + & $\mathrm{v}$ & - & - & - \\
\hline C. pseudotuberculosis & - & + & $\mathrm{v}$ & - & $\mathrm{v}$ & + & $\mathrm{v}$ & + \\
\hline C. renale & - & + & - & + & - & + & - & $\mathrm{v}$ \\
\hline C. striatum & - & - & + & + & + & + & + & - \\
\hline C. urealyticum & + & + & - & + & $\mathbf{v}$ & - & - & - \\
\hline C. xerosis & - & - & + & + & + & + & + & + \\
\hline CDC group G & + & - & $\mathbf{v}$ & + & + & + & $\mathrm{v}$ & $\mathbf{v}$ \\
\hline CDC group F-1 & + & + & $\mathbf{v}$ & + & - & + & + & + \\
\hline
\end{tabular}

${ }^{a}$ The data are from the API-Coryne system database and our observations.

${ }^{b} \mathrm{v}$, variable.

${ }^{c}$ Lacks mycolic acids and includes $\mathrm{CDC}$ group I-2 and CDC group F-2 strains.

${ }^{d}$ Differentiated from $C$. jeikeium and $\mathrm{CDC}$ coryneform group $\mathrm{G}$ by the presence of $\beta$-galactosidase activity.

${ }^{e}$ Differentiated from strains of $\mathrm{CDC}$ coryneform group $\mathrm{G}$ by lack of growth under anaerobic conditions.

an indicator. Enzymatic activities were determined by the API ZYM system (bioMérieux) after $24 \mathrm{~h}$ of incubation. DNase was tested on plates containing agar supplemented with $1 \%$ (vol/vol) Tween 80 after incubation for 5 days at $37^{\circ} \mathrm{C}$. Tests of degradation of gelatin, tyrosine, and starch were performed in nutrient plate culture. Hydrolysis of hippurate was detected after incubation for $2 \mathrm{~h}$ and with ninhydrin as reagent.

Cell wall analysis. Amino acid and sugar determinations were carried out by thin-layer chromatography using the procedure of Staneck and Roberts (15). A reverse-phase HPLC was performed for the determination of mycolic acids (2).

DNA base composition determination. After extraction and purification on cesium chloride gradients, DNA was hydrolyzed with DNase I and nuclease P1 and the $\mathrm{G}+\mathrm{C}$ content in moles percent was determined by chromatography (HPLC) of the deoxynucleotides as described elsewhere (9).

DNA-DNA hybridization. DNA was extracted as described previously (9) except that $10 \mu \mathrm{g}$ of proteinase $\mathrm{K}$ (Sigma) and $20 \mathrm{mg}$ of sodium dodecyl sulfate were added per $\mathrm{ml}$ of lysozyme-treated bacteria. Hybridization between labeled DNA and fragmented DNA preparations was carried out at $60^{\circ} \mathrm{C}$ for $16 \mathrm{~h}$ in 0.42 $\mathrm{M} \mathrm{NaCl}$ by the $\mathrm{S} 1$ nuclease-trichloroacetic acid method $(3,8)$.

Small-subunit rDNA gene sequencing. One hundred nanograms of DNA was used in a PCR to amplify the small-subunit rDNA genes. A pair of primers, corresponding to positions 8 to 28 and 1384 to 1400 of Escherichia coli smallsubunit rDNA sequence was used. The procedures for amplification and direct sequencing of PCR products were as described previously (11).

Phylogenetic methods. The phylogenetic data described below were obtained (i) by using successive alignment and phylogeny procedures and (ii) by reinvestigating deep branching patterns after close relationships were determined (11). A neighbor-joining method (13) was used for a preliminary analysis; resulting topologies were further investigated by maximum likelihood and maximum parsimony methods. Maximum likelihood analyses used the fdnaml program rewritten by G. J. Olsen (University of Illinois, Urbana) and compiled on a HewlettPackard model 700 workstation, while maximum parsimony analyses were performed by using the PAUP program for the Macintosh (16). The robustness of each topology was evaluated under maximum parsimony through 100 bootstrap replications (heuristic search). Trees were plotted by using the njplot program for the Macintosh developed by M. Gouy (Universite Claude Bernard, Lyon, France), which allows the transformation of a formal tree representation (Newick's format) into MacDraw drawings. Only topologies that were found to be similar by all three methods were retained as "true trees." Recent theoretical works have demonstrated that convergence of the results of all three methods is a strong indication that the correct phylogeny has been determined (6).

PCR detection of the diphtheria toxin gene. DNA was prepared and PCR experiments were performed by a previously described procedure (5).

Nucleotide sequence accession numbers. The sequence of strain IBS B10697 has been deposited in the EMBL sequence database under accession number $\mathrm{X} 83955$.

\section{RESULTS AND DISCUSSION}

DNA similarities. The DNA base composition of the four isolates was similar and ranged from 60 to $61 \mathrm{~mol} \% \mathrm{G}+\mathrm{C}$. These data agree with the inclusion of these strains in the genus Corynebacterium, which has been previously suggested on the basis of their mycolic acid composition (2). DNA-DNA hybridization experiments revealed that the four isolates form a single genomic group at the species level. The levels of DNA relatedness between strain IBS B10697 and the three other Corynebacterium sp. isolates were 65,73 , and $93 \%$ for IBS B63473, IBS B22070, and IBS B6369 respectively. Less than 5\% DNA relatedness was found with the type strain of $C$. diphtheriae and with type strains of Corynebacterium species exhibiting a similar $\mathrm{G}+\mathrm{C}$ content, i.e., C. amycolatum, $C$. cystitidis, $C$. jeikeium, C. minutissimum, C. propinquum, C. renale, and $C$. striatum (7).

Phylogenetic analyses. General phylogenetic analyses confirmed that strain IBS B10697 belonged to the robust monophyletic unit grouping all available Corynebacterium sequences (12) as one branch of the CMN taxon (10) (data not shown). More detailed analyses including only Corynebacterium sequences and their closest outgroup, represented by Dietzia maris and Tsukamurella paurometabolum (Fig. 1), were then performed. All three phylogenetic methods placed the new bacterium in a monophyletic unit that included $C$. kutscheri, $C$. diphtheriae, $C$. pseudotuberculosis, and C. ulcerans. However, this cluster was supported by only moderate bootstrap values $(69 \%)$, but the inclusion of the new species in the genus Corynebacterium is supported by high bootstrap values. The relatedness to $C$. diphtheriae, $C$. pseudotuberculosis, and $C$. ulcerans led us to investigate the presence of the tox gene 

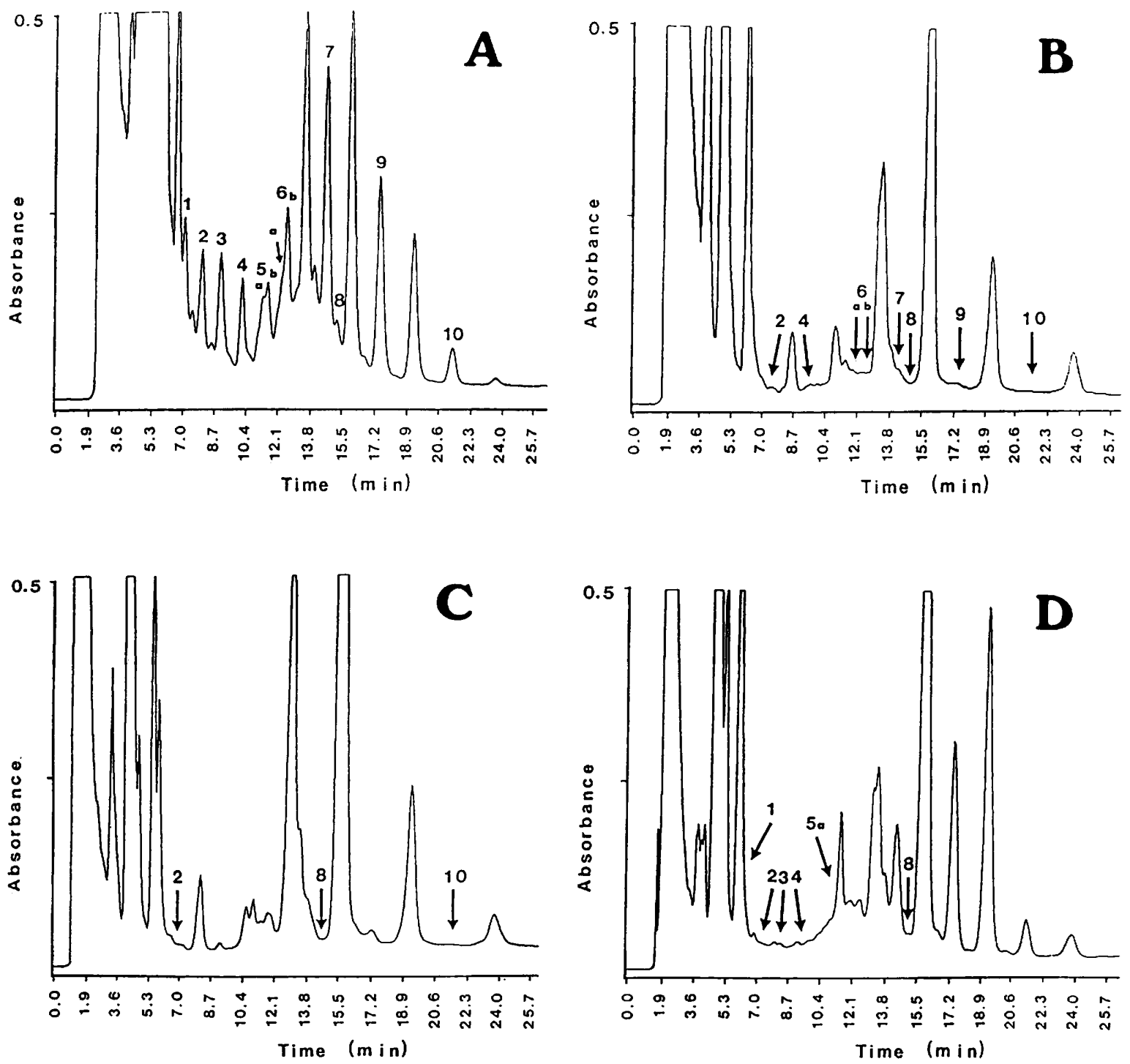

FIG. 2. HPLC patterns of $p$-bromophenacyl esters of mycolic acids from $C$. argentoratense IBS B10697 (A), C. flavescens CIP 69.5T (B), C. minutissimum NCTC $10288^{\mathrm{T}}(\mathrm{C})$, and $C$. mycetoides CIP 55.51T (D). The peaks differentiating $C$. argentoratense from the three other species are numbered.

coding for the diphtheria toxin since these species were found to possess phage $\beta$ with the tox gene (4). A PCR procedure which had been demonstrated to be useful for the detection of this gene (5) did not demonstrate the presence of the gene in any of the four isolates. Because of the low genomic relatedness and since there was less than $96 \%$ similarity in rDNA sequences with any other Corynebacterium species (Table 1), we can conclude, in agreement with the recent criteria for defining a species (14), that strain IBS B10697 is a new species within the genus Corynebacterium. DNA similarities confirm that the four isolates constitute a single distinct genomic species.

Phenotypic characterization. The four isolates are typical coryneform gram-positive rods; they formed creamy colonies $\left(2 \mathrm{~mm}\right.$ in diameter after $48 \mathrm{~h}$ of incubation at $37^{\circ} \mathrm{C}$ ) with an absence of hemolysis on sheep blood agar. They grow well under anaerobic conditions, and a lipid supplement is not required for optimal growth. Biochemical patterns as obtained with the API-Coryne system are similar for the four isolates. These strains are urease and nitrate reductase negative and do not produce acid from lactose, sucrose, maltose, or mannitol.
They ferment glucose, but strain IBS B6369 exhibits a weak acidification from this sugar with the API-Coryne system. These acidifications were confirmed by using a basal heart infusion as described in Materials and Methods, giving a higher sensitivity. Moreover, this strain possesses an alkaline phosphatase activity, whereas the three other strains are negative for this reaction. Differentiation from other Corynebacterium species can be achieved by using the scheme shown in Table 2 . The isolates studied can be differentiated from the two species $C$. flavescens and C. mycetoides, which also ferment glucose alone, by a positive pyrazinamidase test and absence of yellow pigmentation. It should be noted that, in the case of weak glucose fermentation, these strains can be distinguished from C. afermentans strains by using data provided by an API ZYM gallery such as $\alpha$-chymotrypsin activity, which is negative for $C$. afermentans and positive for the four Corynebacterium sp. isolates. Identification of these organisms can also be performed by comparison of patterns of mycolic acids obtained by an HPLC procedure. The four isolates exhibit similar patterns containing 10 peaks which easily distinguish them from the 
biochemically related species $C$. flavescens, $C$. minutissimum, and $C$. mycetoides (Fig. 2). In conclusion, genomic divergence, difference in mycolic acid composition, and biochemical reactions allow the recognition of these four Conynebacterium sp. strains as a new species within the genus Corynebacterium for which the name $C$. argentoratense is proposed. This species was isolated from the throats of patients suffering from tonsillitis, but its clinical relevance remains to be determined since no pathogenic factors were detected and coryneforms are frequently isolated from this site.

Description of Corynebacterium argentoratense sp. nov. Corynebacterium argentoratense (ar.gen.to.ra.ten'se. N.L. adj. from Argentoratum, Latin name of the city of Strasbourg, where the organism was isolated). The description is based on the data of the four strains included in this study.

Bacteria are nonmotile pleomorphic rods that are gram positive but not partially acid-fast and nonsporing. Cells are arranged in palisades or V-shaped forms. They are catalase positive, oxidase negative, and facultatively anaerobic. The bacteria grow on blood agar as circular acuminated creamy colonies (diameter, $2 \mathrm{~mm}$ ) after $48 \mathrm{~h}$ of incubation at $37^{\circ} \mathrm{C}$ which are not hemolytic. They are not lipid requiring. Nitrate is not reduced, and tyrosine, gelatin, DNA, and urea are not degraded or hydrolyzed. Esculin is not hydrolyzed. Hydrolyses of starch and hippurate occur variably. Pyrazinamidase, esterase lipase, cystine arylamidase, and $\alpha$-chymotrypsin are present. Production of esterase, leucine arylamidase, and acid phosphatase is variable, and alkaline phosphatase is usually not produced. Pyrrolidonylamidase, $\beta$-glucuronidase, $\beta$-galactosidase, $\alpha$-glucosidase, and $N$-acetyl- $\beta$-glucosaminidase are not produced. Acid is produced from D-glucose and fructose but not from sucrose, maltose, lactose, galactose, D-xylose, trehalose, glycogen, or D-mannitol. Acidification from ribose occurs variably. The cell wall contains meso-diaminopimelic acid, arabinose, and galactose. Mycolic acids of short chain lengths $\left(\mathrm{C}_{26}\right.$ to $\left.\mathrm{C}_{36}\right)$ are present. DNA base composition is 60 to 61 mol\% $\mathrm{G}+\mathrm{C}$ (HPLC procedure). $C$. argentoratense strains were isolated from human throat specimens. The type strain is strain IBS B10697 (CIP 104296). It was isolated in Strasbourg. This strain has all the above properties for the species. Starch, but not hippurate, is hydrolyzed. Acid is produced from ribose. Esterase and acid phosphatase, but not alkaline phosphatase, are present.

\section{ACKNOWLEDGMENTS}

We thank H. G. Trüper for advice concerning the Latin name. We are grateful to C. Gallion and B. Muller for skillful technical assistance.

\section{REFERENCES}

1. Collins, M. D., and C. S. Cummins. 1986. Genus Corynebacterium, Lehmann and Neumann 1896, 350, p. 1266-1276. In P. H. A. Sneath, N. S. Mair, M. E. Sharpe, and J. G. Holt (ed.), Bergey's manual of systematic bacteriology, vol. 2. The Williams \& Wilkins Co., Baltimore.

2. De Briel, D., F. Couderc, P. Riegel, F. Jehl, and R. Minck. 1992. Highperformance liquid chromatography of corynomycolic acids as a tool in identification of Corynebacterium species and related organisms. J. Clin. Microbiol. 30:1407-1417.

3. Grimont, P. A. D., M. Y. Popoff, F. Grimont, C. Coynault, and M. Lemelin. 1980. Reproductibility and correlation study of three deoxyribonucleic acid hybridization procedures. Curr. Microbiol. 4:325-330.

4. Groman, N., J. Schiller, and J. Russel. 1984. Corynebacterium ulcerans and Corynebacterium pseudotuberculosis responses to DNA probes derived from corynephage $\beta$ and Connebacterium diphtheriae. Infect. Immun. 45:511517.

5. Hauser, D., M. R. Popoff, M. Kiredjian, P. Boquet, and F. Bimet. 1993. Polymerase chain reaction assay for diagnosis of potentially toxinogenic Corynebacterium diphtheriae strains: correlation with ADP-ribosylation activity assay. J. Clin. Microbiol. 31:2720-2723.

6. Kim, J. 1993. Improving the accuracy of phylogenetic estimation by combining different methods. Syst. Biol. 42:331-340.

7. Pitcher, D. G. 1983. Deoxyribonucleic acid base composition of Conynebacterium diphtheriae and other corynebacteria with cell wall type IV. FEMS Microbiol. Lett. 16:291-295.

8. Riegel, P., D. de Briel, G. Prévost, F. Jehl, and H. Monteil. 1994. Genomic diversity among Corynebacterium jeikeium strains and comparison with biochemical characteristics and antimicrobial susceptibilities. J. Clin. Microbiol. 32:1860-1865.

9. Riegel, P., P. A. D. Grimont, D. de Briel, E. Ageron, F. Jehl, M. Pelegrin, H. Monteil, and R. Minck. 1992. Corynebacterium group D-2 ("Corynebacterium urealyticum") constitutes a new genomic species. Res. Microbiol. 143:307313.

10. Ruimy, R., P. Boiron, V. Boivin, and R. Christen. 1994. A phylogeny of the genus Nocardia deduced from the analysis of small-subunit ribosomal DNA sequences, including transfer of Nocardia amarae to the genus Gordona as Gordona amarae comb. nov. FEMS Microbiol. Lett. 123:261-268.

11. Ruimy, R., V. Breittmayer, P. Elbaze, B. Lafay, O. Boussemart, M. Gauthier, and R. Christen. 1994. A general phylogenetic analysis of the family Vibrionaceae (Vibrio, Photobacterium, Aeromonas, Plesiomonas) deduced from the comparison of nearly complete $16 S$ rRNA sequences. Int. J. Syst. Bacteriol. 44:416-426.

12. Ruimy, R., P. Riegel, P. Boiron, H. Monteil, and R. Christen. Phylogeny of the genera Corynebacterium, Rhodococcus and Gordona deduced from analyses of small-subunit ribosomal DNA sequences. Submitted for publication.

13. Saitou, N., and M. Nei. 1987. The neighbor-joining method: a new method for reconstructing phylogenetic trees. Mol. Biol. Evol. 4:406-425.

14. Stackebrandt, E., and B. M. Goebel. 1994. Taxonomic note: a place for DNA-DNA reassociation and 16S rRNA sequence analysis in the present species definition in bacteriology. Int. J. Syst. Bacteriol. 44:846-849.

15. Staneck, J. L., and G. D. Roberts. 1974. Simplified approach to identification of aerobic actinomycetes by thin-layer chromatography. Appl. Microbiol. 28:226-231.

16. Swofford, D. 1990. PAUP: phylogenetic analysis using parsimony, version 3.0. Illinois Natural History Survey, Champaign. 